\title{
DR-53. SYNTHESIS OF REGULAR POLYHEXENE IN PERFLUOROMETHYLCYCLOHEXANE
}

\author{
$\underline{\text { S. V. Yakovlev }}^{1}$, G. A. Artem'ev', N. A. Rasputin'1, P. G. Rusinov'², I. E. Nifant'ev' ${ }^{3,4}$, \\ V. N. Charushin ${ }^{1,5}$, D. S. Kopchuk ${ }^{1,5}$ \\ ${ }^{1}$ I. Ya. Postovsky Institute of Organic Synthesis UB RAS, \\ S. Kovalevskoy/Akademicheskaya St., 20/22, Yekaterinburg, 620990, Russia \\ ${ }^{2}$ NIKA-Petro Tech, off. 5, Tolmacheva St., 22, Yekaterinburg, 620075, Russia \\ ${ }^{3}$ M. V. Lomonosov Moscow State University, Chemistry Department, \\ Leninskie Gory St., 1-3, Moscow, 119991, Russia \\ ${ }^{4}$ A.V. Topchiev Institute of Petrochemical Synthesis RAS, \\ Leninsky Pr., 29, Moscow, 119991, Russia \\ ${ }^{5}$ Ural Federal University of the first President of Russia B. N. Yeltsin, \\ Mira St., 19, Yekaterinburg, 620002, Russia \\ E-mail: seregayakovlev@mail.ru
}

Hexene-1 based polymers are of practical interest from the point of view of the further production of anti-turbulent additives to reduce the resistance of the oil flow in the field of turbulence. Currently, there are such methods of polymerization of higher olefins as polymerization in the monomer mass, in the block, in monomer droplets that are not miscible with the medium. It should also be noted the possibility of using perfluorinated alkanes (PFA) as solvents for polymerization. Their main advantage is the fact that they do not dissolve polymers of higher alpha-olefins and are very partially mixed with other polar and non-polar liquids. These qualities are facilitated by their separation in the process of changing the medium in suspension to another non-solvent.

The polymer density is approximately half that of PFA, and the particles are easily decanted after the reaction. Suspension polymerization in perfluoroalkanes can be realised either by the classical path, where monomer droplets are converted into a solid polymer, or through suspension polymerization, when the monomer is mixed with the medium, and the polymer precipitates as a suspension as in case of ethylene polymerization in alkanes media. The time of polymer synthesis can be reduced to several hours instead of several days for block technology. The only disadvantage is the relatively high cost of perfluoroalkanes. However, since they are practically not consumed in the polymerization process and that their penetration into immiscible liquids is insignificant, the loss of PFA can be minimized. In this report, we propose an improved scaled method for the polymerization of hexene-1 in the perfluoromethylcyclohexane medium (the amount of monomer is 2,4 liters). In contrast to the previously considered similar procedures, in our case the polymer was isolated in its pure form and characterized. During the polymerization, the catalyst described earlier was used.

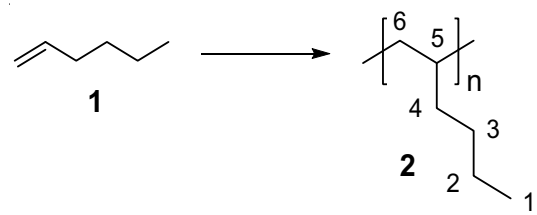

This work was supported by the Russian Science Foundation (Ref. № 18-13-00365). 